\title{
The relation between publication rate and financial conflict of interest among physician authors of high-impact oncology publications: an observational study
}

\author{
Victoria Kaestner BA, Jonathan B. Edmiston BA, Vinay Prasad MD MPH
}

\section{Abstract}

Background: Despite the abundant research on financial conflict of interest regarding provider behaviour and the interpretation and results of research, little is known about the relation between these conflicts in academia and the trajectory of one's academic career. We performed a study to examine whether the presence of financial ties to drug makers among academics is associated with research productivity.

Methods: We hand-searched 3 high-impact general medical journals (New England Journal of Medicine, JAMA and The Lancet) and 3 high-impact oncology journals that publish original science (The Lancet Oncology, Journal of Clinical Oncology and Journal of the National Cancer Institute) to identify physicians based in the United States who were first or last authors on original papers on hematologic or oncologic topics that appeared in 2015. We ascertained their publication history from Scopus and their personal and research payments from the Centers for Medicare \& Medicaid Services' Open Payments Web site (2013-2015). The strength of association between general (personal) financial payments from 2013 to 2015 and publications from 2013 to 2016 was determined by multivariate regression.

Results: Our sample consisted of 435 physicians who had authored a median of 140 publications, earning a median h-index of 36 and a median of 5639 citations. The median total of general payments from 2013 to 2015 was US\$3282 (range \$0-\$3.4 million), and the median amount of research payments was US\$3500 (range \$0-\$23 million). General payments were associated with contemporary publications, with an increase of 1.99 papers (95\% confidence interval $[\mathrm{Cl}] 1.1$ to 2.9$)$ per $\$ 10000$ in payments. This association persisted in multivariate analysis after adjustment for prior publications, seniority and research payments $(0.84$ papers [95\% $\mathrm{Cl} 0.15$ to 1.5$]$ per $\$ 10000$ in payments).

Interpretation: The findings suggest that there is a positive association between personal payments from drug makers and publications, and that this association persists after adjustment for prior publications, time since medical school graduation and research payments.

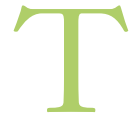

he receipt of payments or other valuable or desired items from the pharmaceutical industry is considered a financial conflict of interest among health care providers. ${ }^{1}$ However, it has been found to be widespread $^{2-7}$ and has been linked to provider behaviour. ${ }^{8-10}$ Receipt of a meal at which a specific drug is promoted has been linked to increased prescribing of that drug. ${ }^{8}$ Acceptance of payments from the biopharmaceutical industry has been associated with increased brand-name prescribing. ${ }^{9,10}$ Industry relationships are particularly common among academic scientists. ${ }^{11}$ In the United States, many research projects have been facilitated by section 6002 of the Affordable Care Act, the so-called sunshine clause, which mandates forprofit companies marketing a health care product to report payments to prescribing physicians. ${ }^{12}$
Conflict may be even more apparent with respect to the results of research and their interpretation. A Cochrane review of 75 papers showed consistently that industrysponsored studies have more favourable efficacy results and conclusions than do studies not sponsored by industry while minimizing harms. ${ }^{13}$ Other investigators have shown that

Competing interests: Vinay Prasad is funded by the Laura and John Arnold Foundation. No other competing interests were declared.

This article has been peer reviewed.

Correspondence to: Vinay Prasad, prasad@ohsu.edu

CMAJ Open 2018. DOI:10.9778/cmajo.20170095 
industry-sponsored cost-effectiveness analyses are more likely to reach favourable conclusions. ${ }^{14}$ Recently, Ahn and colleagues ${ }^{15}$ reported that a principal investigator's personal financial ties to drug makers are linked to positive study conclusions.

Despite the abundant research on financial conflict of interest regarding provider behaviour and the interpretation and results of research, little is known about the relation between these conflicts in academia and the trajectory of one's academic career. Some investigators are concerned that excessive stigma regarding financial conflict may even harm physicians' careers, ${ }^{16,17}$ as publications constitute a metric of academic success. Prior studies have explored the relation between payments to investigators and the outcomes of research, ${ }^{18-24}$ the relation between payments or gifts and prescriber behaviour ${ }^{9,10}$ and even editorial attitudes toward drug products. ${ }^{25,26} \mathrm{We}$ performed a study to examine whether the presence of financial ties to drug makers among academics is associated with research productivity. We also sought to determine whether such associations persist after accounting for seniority, prior scholarship and total research payments.

\section{Methods}

\section{Sample}

Our study was conducted between Oct. 1 and Dec. 31, 2016. We sought to create a set of clinician-researchers who were first or last author on a cancer paper in a top journal in 2015 . We focused on hematologist oncologists because of the unique concern of conflict in this field. ${ }^{27}$ Authors had to be based in the US, as the Affordable Care Act's sunshine clause mandates disclosure only for these people. Authors had to be clinicians (MD or DO [Doctor of Osteopathic Medicine]), as the disclosure clause applies only to practising doctors.

We hand-searched the 3 general medical journals with the highest impact factor (New England Fournal of Medicine, $7 \mathrm{AMA}$ and The Lancet) and the 3 oncology journals with the highest impact factor that publish original science (The Lancet Oncology, Fournal of Clinical Oncology and Fournal of the National Cancer Institute) for all original articles on a hematologic or oncologic topic appearing in 2015. We extracted the title, the first and last authors, and whether the author was based in the US or abroad based on the disclosed institutional association. We then eliminated all authors who did not have an MD degree, were based outside of the US or worked for the biopharmaceutical industry. Biopharmaceutical employees were eliminated as we were interested in the relation between financial conflicts and career productivity among academic oncologists. Receipt of funding was not among the inclusion criteria. The journals were searched by 2 reviewers; differences were resolved by discussion.

\section{Identification of financial conflicts}

We searched the Open Payments Web site of the Centers for Medicare \& Medicaid Services (https://www.cms.gov/ openpayments/) for payments from biopharmaceutical com- panies with at least 1 product on the US market (companies that do not yet have a product on the US market are not included in the sunshine clause). General and research payments were recorded for the period 2013-2015 (prior years are not included in the sunshine clause's disclosures). General payments are those typically made directly to the physician, often for consulting or honoraria, whereas research payments are typically paid to the institution.

\section{Documentation of publication records}

For each author in our data set, we searched Scopus, using "Author Search," and recorded his or her total publications, total citations and h-index. Limited evidence suggests that Scopus is highly accurate at identifying an author's publications. $^{28}$ We then exported the author's publications to Excel and sorted by year of publication. We ascertained the number of papers published before 2013 and the number of papers published from 2013 to 2016.

\section{Years since medical school graduation}

For each author, we performed a Google search to identify a Web site that listed the number of years that he or she had been in practice since completing medical school. In cases in which the year of graduation was found, we subtracted this number from 2016 to calculate the number of years since graduation.

\section{Statistical analysis}

We summarized descriptive statistics of our data set, after removing outliers by leverage and Cook's distance for our principal regression analysis. We performed simple linear regression analysis to ascertain the strength of association between general (or personal) financial payments from 2013 to 2015 and publications from 2013 to 2016. We then expanded this regression to a multivariate model, adjusting for years since medical school, research payments and publications before 2013. Our multivariate regression asked the question: "Adjusting for career productivity, seniority and research funding, is there a persistent association between general payments to physicians and scholarly output?" All included variables in the model were prespecified, and no additional covariates were examined. Residuals were examined. Payments are expressed in 2015 US dollars. Our analysis was performed with the use of Stata version 13.0 (StataCorp).

\section{Ethics approval}

As our study used information that is publicly available only, it did not require institutional ethics review board approval.

\section{Results}

We identified 435 physician authors who were first or last author on a hematology oncology paper in the journals searched. The characteristics of these doctors are shown in Table 1. Notably, the median number of years since medical school was 24. The physicians had authored a median of 140 publications, earning a median h-index of 36 and a 


\begin{tabular}{|c|c|c|c|}
\hline \multicolumn{4}{|c|}{$\begin{array}{l}\text { Table 1: Characteristics of physicians with a first- or last-authored paper on a } \\
\text { hematologic or oncologic topic in a high-impact journal in } 2015\end{array}$} \\
\hline Characteristic & Median (range) & $\begin{array}{l}\text { 25th } \\
\text { percentile }\end{array}$ & $\begin{array}{l}\text { 75th } \\
\text { percentile }\end{array}$ \\
\hline $\begin{array}{l}\text { Frequency as corresponding } \\
\text { author }\end{array}$ & $1(0$ to 3$)$ & 0 & 1 \\
\hline $\begin{array}{l}\text { Years since medical school } \\
\text { graduation }\end{array}$ & 24 (1 to 61$)$ & 17 & 33 \\
\hline No. of publications & 140 ( 1 to 1906$)$ & 52 & 253 \\
\hline No. of citations & 5639 (0 to 116544$)$ & 1452 & 13448 \\
\hline h-index & 36 (0 to 172$)$ & 18 & 56 \\
\hline No. of papers before 2013 & $86(0$ to 1486$)$ & 24 & 175 \\
\hline No. of papers in 2013-2016 & 40 (0 to 423$)$ & 22 & 68 \\
\hline Total general payments, $\$$ & 3282 (0 to 3369 193) & 0 & 32578 \\
\hline Total research payments, $\$$ & 3500 (0 to 23132162$)$ & 0 & 691797 \\
\hline
\end{tabular}

median of 5639 citations. The median total of general payments from 2013 to 2015 was $\$ 3282$, although the range was wide (\$0-\$3.4 million). The median amount of research payments from 2013 to 2015 was $\$ 3500$ (range $\$ 0$ to $>\$ 23$ million). Waterfall plots of general and research payments are presented in Figure 1 and show the distribution of payments to this group.

Simple linear regression to examine the correlation between papers published before 2013 and those published in 2013-2016 showed a statistically significant correlation (slope $[\beta$ coefficient $]=0.19,95 \%$ confidence interval $[\mathrm{CI}] 0.17$ to 0.20 ) (Figure 2). We then performed our primary analysis of interest, examining to what degree general payments were associated with publications. Again, we noted a significant relation, with a slope of 1.99 (95\% CI 1.07 to 2.90), meaning an increase of 1.99 papers per every $\$ 10000$ increase in payments (Figure 3). Full details of the analysis are given in Table 2.

Multivariate analysis confirmed a persistent positive association between personal payments and publications, with a smaller magnitude of effect, 0.84 (95\% CI 0.15 to 1.5$)$ papers per every $\$ 10000$ in payments (Table 2). This means an increase of 0.84 papers per every $\$ 10000$ in payments. Given that the median number of papers published in this period was 40 , we found an increase in publications of $5.0 \%$ (unadjusted analysis) or $2.1 \%$ (adjusted analysis) per $\$ 10000$ in payments.

\section{Interpretation}

We found that, among US-based physicians who had a firstor last-authored hematology oncology paper in a high-impact journal, personal payments from the biopharmaceutical industry were positively associated with publication, and this relation persisted even after adjustment for years since graduation from medical school (a measure of seniority), prior publications and pharmaceutical company research funding reported under the sunshine clause of the Affordable Care Act. Our

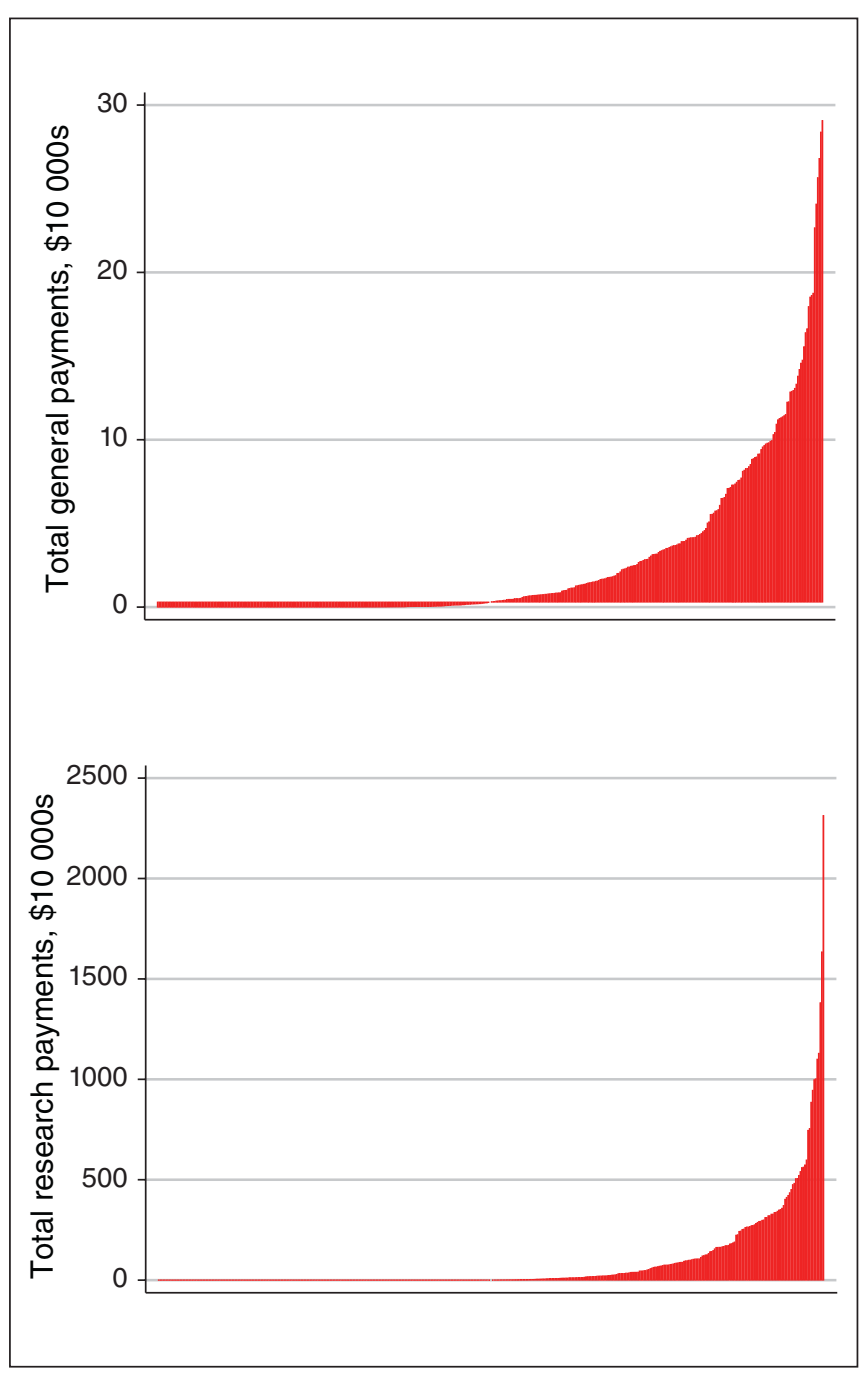

Figure 1: Waterfall plots showing the distribution of general payments (top) and research payments (bottom). Each physician is represented by 1 vertical bar, and the baseline is set to the median payment. 


\section{Research}

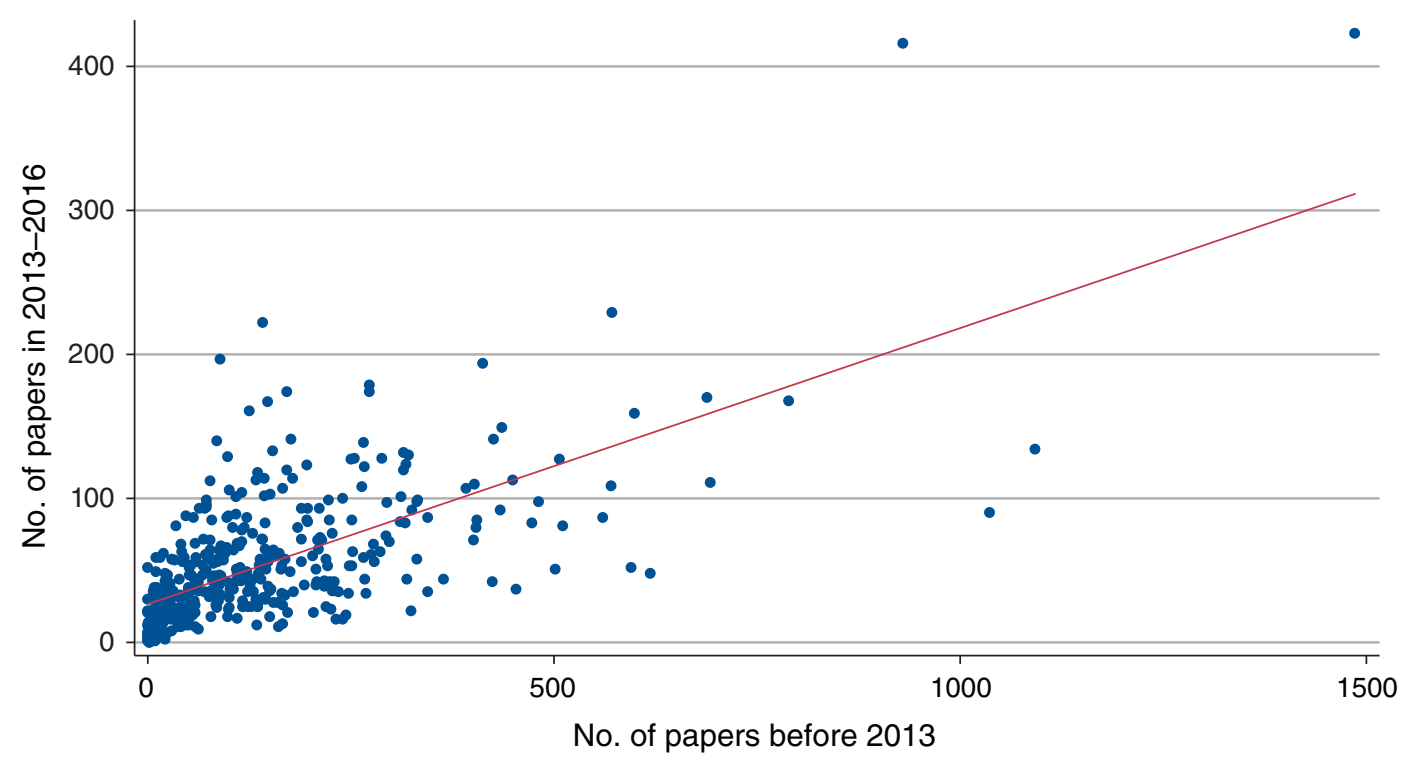

$R^{2}=0.46 \quad \beta$ coefficient $=0.19$

Figure 2: Correlation between publications before 2013 and those in 2013-2016.

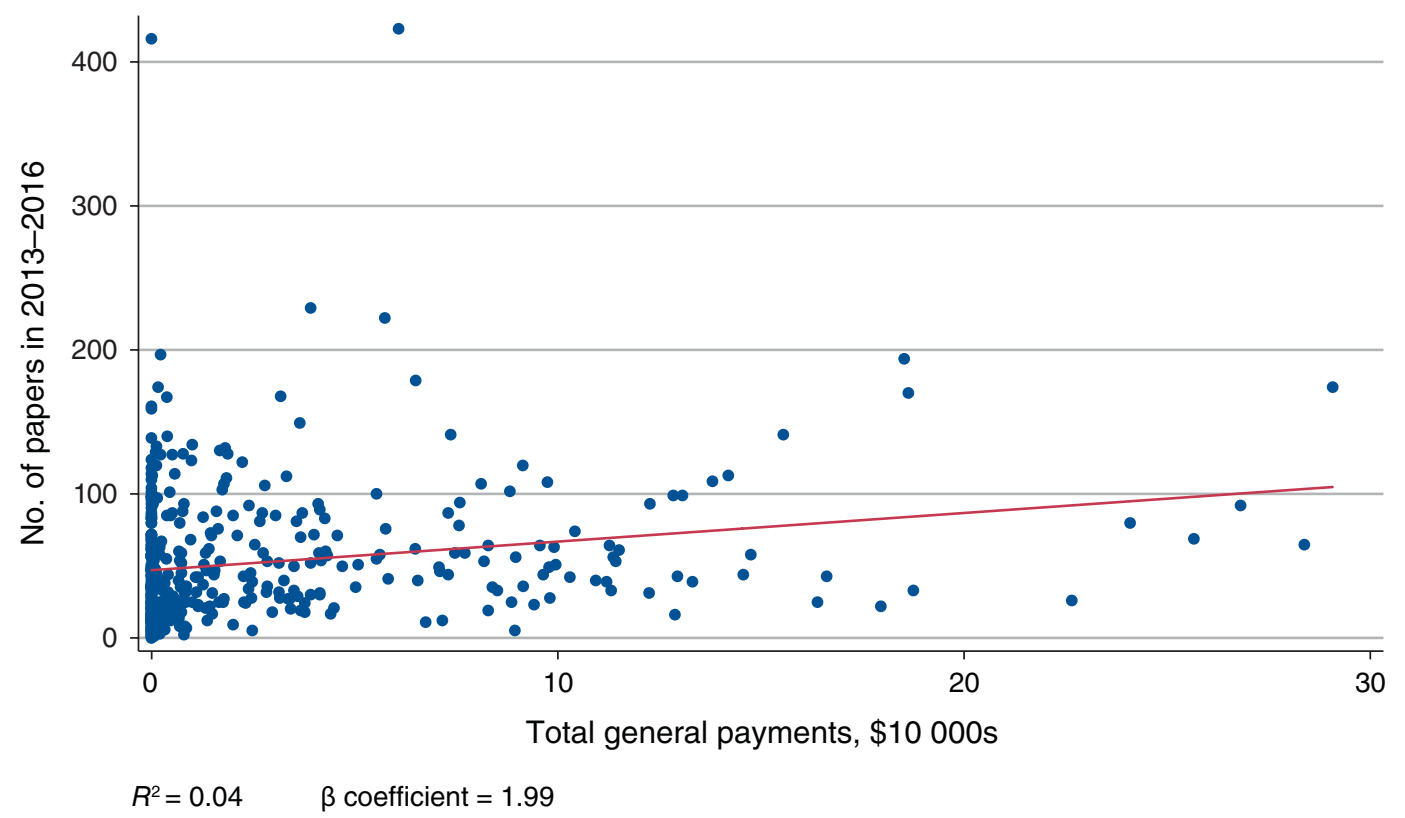

Figure 3: Correlation between general (personal) payments from the biopharmaceutical industry to physicians in 2013-2015 and number of papers published in 2013-2016. 
Table 2: Simple and multivariate regression examining the association between general payments in 2013-2015, research payments in 2013-2015, years since medical school graduation and prior publications, and publications in 2013-2016

\begin{tabular}{|lc|}
\hline Variable & Slope $(95 \% \mathrm{Cl})$ \\
\hline Simple linear regression & \\
\hline $\begin{array}{l}\text { General payments in 2013-2015, } \\
\$ 10 \text { 000s }\end{array}$ & $1.99(1.07$ to 2.90$)$ \\
\hline Multivariate regression & $\beta$ coefficient $(95 \% \mathrm{Cl})$ \\
\hline $\begin{array}{l}\text { General payments in 2013-2015, } \\
\$ 10 \text { 000s }\end{array}$ & $0.836(0.15$ to 1.52$)$ \\
\hline $\begin{array}{l}\text { Papers published before } 2013 \\
\text { Years since graduating medical } \\
\text { school }\end{array}$ & $0.236(0.213$ to 0.260$)$ \\
\hline Total research payments, $\$ 10$ 000s & $0.0255(0.019$ to 0.040$)$ \\
\hline Note: $\mathrm{Cl}=$ confidence interval. & \\
\hline
\end{tabular}

findings suggest that career productivity is positively affected by personal payments from drug makers.

Some investigators are concerned that current policies against conflict of interest, which largely are confined to forms of disclosure, may be used to cast aspersions on conflicted biomedical researchers. ${ }^{29}$ The editor-in-chief of the New England Fournal of Medicine has been critical of policies that restrict review or editorial articles to authors free of financial conflicts. ${ }^{30}$ Our results provide a reassuring note. The acceptance of industry payments is not associated with fewer publications; thus, prohibitions against financial conflict of interest are not currently so daunting that they hinder researchers' careers. Further prohibitions may be considered.

What drives our observation? There are 2 distinct possibilities underlying the association we report. First, the biopharmaceutical industry preferentially seeks and compensates the advice of physicians who are likely to have higher scholarly outputs. Alternatively, the acceptance of personal payments drives scholarly output, perhaps owing to greater financial security, novel ideas for scholarship or even ghost author publications. ${ }^{31-33}$ In other words, although we found an association, we are unable to show directionality. We are unable to show which came first, the increased publications or the increased funding. We are unable to establish causality. Because the sunshine clause is not retroactive, we are unable to perform a longitudinal analysis on this question. This limitation, however, provides additional support for the importance of public disclosure, which permits these types of investigations. In the future, decades of public disclosure of financial conflict will facilitate important analyses of the implications of conflict.

Finally, our paper shows that the acceptance of personal payments is not used to marginalize or hinder conflicted researchers - contradicting speculation that current conflict of interest policies are excessively restrictive ${ }^{23}-$ as these authors have more, not fewer, publications.

\section{Limitations}

As with most observational studies, our study can highlight only an association and not causation. Ours was a crosssectional study, and we are unable to conclude whether accepting money from the drug industry improves a researcher's scholarly output. Yet, experts have postulated that financial ties with the drug industry may increase cross-pollination and ideas, driving scholarly work. ${ }^{34}$

Second, although we were able to show that the association between personal payments to physicians and publication persisted after adjustment for prior publications, years since graduating from medical school and research payments, we did not examine more covariates. It is possible that other, unexamined covariates are driving the relation. We were limited to publicly available covariates. We did consider total citation count and the h-index, measures of research impact; however, these were highly correlated with publication by Pearson correlation and would introduce collinearity to models rather than refined prediction. We encourage other investigators to explore this relation in different cohorts of researchers.

The third limitation is the time span of our study. We were limited by available dates in public disclosure, and we encourage other researchers to look for long-term patterns in the years to come.

Finally, we restricted our analysis to hematologist oncologists, and we cannot generalize our findings to other specialists. In addition, we chose first and last authors to create a manageable data set and to seek those most interested in academics, and our work should not be generalized to all researchers. Future work exploring both of these factors is needed.

\section{Conclusion}

Our findings suggest that personal financial conflict of interest is linked to more publications among hematologist oncologists authoring biomedical articles in the US. This finding should be further explored; if validated, it may lead to consideration of policies to provide alternative incentives to physicians who decline industry payments. Policy-makers may be reassured that current conflict-of-interest policies have not resulted in lower scholarly output among conflicted physicians.

\section{References}

1. Prasad V, Rajkumar SV. Conflict of interest in academic oncology: moving beyond the blame game and forging a path forward. Blood Cancer 7 2016;6:e489.

2. Campbell EG. Doctors and drug companies - scrutinizing influential relationships. N Engl 7 Med 2007;357:1796-7.

3. Campbell EG, Rao SR, DesRoches CM, et al. Physician professionalism and changes in physician-industry relationships from 2004 to 2009. Arch Intern Med 2010;170:1820-6.

4. Boothby A, Wang R, Cetnar J, et al. Effect of the American Society of Clinical Oncology's conflict of interest policy on information overload. $\mathscr{f} A M A$ Oncol 2016;2:1653-4.

5. Mitchell AP, Basch EM, Dusetzina SB. Financial relationships with industry among national comprehensive cancer network guideline authors. $7 A M A$ Oncol 2016;2:1628-31.

6. Marshall DC, Moy B, Jackson ME, et al. Distribution and patterns of industryrelated payments to oncologists in 2014. 7 Natl Cancer Inst 2016;108:pii: djw163.

7. Tao DL, Boothby A, McLouth J, et al. Financial conflicts of interest among hematologist-oncologists on Twitter. FAMA Intern Med 2017;177:425-27.

8. DeJong C, Aguilar T, Tseng C, et al. Pharmaceutical industry-sponsored meals and physician prescribing patterns for Medicare beneficiaries. $7 A M A$ Intern Med 2016;176:1114-22. 
9. Yeh JS, Franklin JM, Avorn J, et al. Association of industry payments to physicians with the prescribing of brand-name statins in Massachusetts. $7 A M A$ Intern Med 2016;176:763-8.

10. Fleischman W, Agrawal S, King M, et al. Association between payments from manufacturers of pharmaceuticals to physicians and regional prescribing: cross sectional ecological study. BM7 2016;354:i4189.

11. Zinner DE, Bolcic-Jamkovic D, Clarridge B, et al. Participation of academic scientists in relationships with industry. Health Aff (Millwood) 2009;28:1814-25.

12. Richardson EC, Saver R, Lott R, et al. The Physician Payments Sunshine Act. Health Affairs 2014 Oct. 2 [Epub ahead of print]. doi:10.1377/hpb20141002.272302.

13. Lundh A, Sismondo S, Lexchin J, et al. Industry sponsorship and research outcome. Cochrane Database Syst Rev 2012(2):MR000033.

14. Bell CM, Urbach DR, Ray JG, et al. Bias in published cost effectiveness studies: systematic review. BM7 2006;332:699-703.

15. Ahn R, Woodbridge A, Abraham A, et al. Financial ties of principal investigators and randomized controlled trial outcomes: cross sectional study. BMF 2017;356:i6770.

16. Shaywitz DA, Stossel TP. It's time to fight the 'pharmascolds': getting drugs to market is much harder than the media lets on. The Wall Street Fournal [New York] [updated 2009 Apr. 8]. Available: https://www.wsj.com/articles/ SB123914780537299005 (accessed 2018 Jan. 25).

17. Shaywitz D. How academic orthodoxy is enforced: a valuable lesson from a distinguished pharmascold. Forbes Magazine [Jersey City, NJ] 2011 Sept. 18. Available: https://www.aei.org/publication/how-academic-orthodoxy-is -enforced-a-valuable-lesson-from-a-distinguished-pharmascold/print/ (accessed 2018 Jan. 25).

18. Amiri AR, Kanesalingam K, Cro S, et al. Does source of funding and conflict of interest influence the outcome and quality of spinal research? Spine 72014 ; $14: 308-14$.

19. Perlis HR, Perlis CS, Wu Y, et al. Industry sponsorship and financial conflict of interest in the reporting of clinical trials in psychiatry. Am 7 Psychiatry 2005; 162:1957-60.

20. Perlis CS, Harwood M, Perlis RH. Extent and impact of industry sponsorship conflicts of interest in dermatology research. 7 Am Acad Dermatol 2005;52: 967-71.

21. Pang WK, Yeter KC, Torralba KD, et al. Financial conflicts of interest and their association with outcome and quality of fibromyalgia drug therapy randomized controlled trials. Int 7 Rheum Dis 2015;18:606-15.

22. Riechelmann RP, Wang L, O'Carroll A, et al. Disclosure of conflicts of interest by authors of clinical trials and editorials in oncology. 7 Clin Oncol 2007;25: 4642-7.

23. Friedman LS, Richter ED. Relationship between conflicts of interest and research results. 7 Gen Intern Med 2004;19:51-6.

24. Kjaergard LL, Als-Nielsen B. Association between competing interests and authors' conclusions: epidemiological study of randomised clinical trials published in the BMF. BMF 2002;325:249.
25. Wang AT, McCoy CP, Murad MH, et al. Association between industry affiliation and position on cardiovascular risk with rosiglitazone: cross sectional systematic review. $B M 7$ 2010;340:c1344.

26. Fugh-Berman A, McDonald CP, Bell AM, et al. Promotional tone in reviews of menopausal hormone therapy after the Women's Health Initiative: an analysis of published articles. PLoS Med 2011;8:e1000425.

27. Prasad V, Rajkumar SV. Conflict of interest in academic oncology: moving beyond the blame game and forging a path forward. Blood Cancer 7 2016;6: e489.

28. Kawashima H, Tomizawa H. Accuracy evaluation of Scopus author ID based on the largest funding database in Japan. Scientometrics 2015;103:1061-71.

29. Rosenbaum L. Conflicts of interest: part 1: Reconnecting the dots - reinterpreting industry-physician relations. NEngl F Med 2015;372:1860-4.

30. Drazen JM. Revisiting the commercial-academic interface. N Engl 7 Med 2015; 372:1853-4.

31. Gøtzsche PC, Hróbjartsson A, Johansen HK, et al. Ghost authorship in industry-initiated randomised trials. PLoS Med 2007;4:e19.

32. Lissoni F, Montobbio F. Guest authors or ghost inventors? Inventorship and authorship attribution in academic science. Eval Rev 2015;39:19-45.

33. Wislar JS, Flanagin A, Fontanarosa PB, et al. Honorary and ghost authorship in high impact biomedical journals: a cross sectional survey. BM7 2011;343:d6128.

34. Flier JS. White paper: conflicts of interest and academic industry relationships. Cambridge (MA): Harvard University; 2009. Available: https://hms.harvard. edu/sites/default/files/assets/About_Us/Deans_Rep/files/white_paper_flier.pdf (accessed 2017 Nov. 1).

Affiliations: Division of Hematology and Medical Oncology (Kaestner, Prasad), Knight Cancer Institute, Oregon Health and Science University; School of Medicine (Edmiston), Oregon Health and Science University; Department of Preventive Medicine and Public Health (Prasad); Center for Health Care Ethics (Prasad), Oregon Health and Science University, Portland, Ore.

Contributors: Vinay Prasad conceived and designed the study and acquired the data. Jonathan Edmiston analyzed the data and created the figures. Victoria Kaestner and Vinay Prasad drafted the manuscript, and Jonathan Edmiston revised the manuscript for important intellectual content. All of the authors analyzed and interpreted the data, gave final approval of the version to be published and agreed to be accountable for all aspects of the work.

Supplemental information: For reviewer comments and the original submission of this manuscript, please see www.cmajopen.ca/content/6/1/ E57/supp1/DC1 